\title{
MUSLIM MODERAT \\ BARAT VERSUS ISLAM
}

\author{
Zaim Rais \\ e-Mail : zaimraisdhamra@gmail.com \\ UIN Imam Bonjol Padang
}

\begin{abstract}
Abstrak : Sebuah istilah muncul kepermungkaan setelah berkembangnya Isu radikalisme dan terorisme yang sering dihubung-hubungkan dengan Umat Islam, yaitu moderat. Terjadi perdebatan ditengah-tengah kehidupan hari ini dalam memahami makna moderat tersebut, bagaiaman dan siapa yang dianggap sebagai muslim yang moderat atau berpaham moderat. Ada kebingungan interpertasi dalam memahami makna ini, terutama jika dilihat dari perspektif Islam dan diluar Islam.
\end{abstract}

Kata Kunci : Muslim, Barat, Moderat

\section{A. Pendahuluan}

Melihat begitu banyaknya istilah yang ambigu yang ditempelkan kepada umat Islam, datangnya bukan dari kalangan umat Islam sendiri, yang membuat bingung dan sampai memecah belah umat, dengan mengelompokkan Islam menjadi bagaian-bagian tertentu tergantung kepada siapa yang memunculkan istilah tersebut dan untuk kepentingan siapa. ini adalah bentuk perang pemikiran yang ditembakkan kepada umat Islam, sehingga ada yang kena pengaruh, juga ada yang selamat dan ada yang terpecah karena serangan tadi.

Dalam beberapa dekade ini, perseteruan politik dan idiologi yang menjadikan Umat Islam sebagai subjek dan topik pembicaraan telah menghadirkan perdebatan yang panjang dan alot diantara kalangan elit politik dan cenkdiawan serta ilmuwan, mengenai peran dan pengaruh Islam terhdap perkembangan dunia, yang mana kemajuan Islam akan menjadi ancaman bagi eksistensi mereka dan kehidupan ini.

Mereka menyadari, untuk menghadapi Umat Islam secara keseluruhan dan dengan jalur perang tidak akan memberikan keuntungan, atau bahkan mengalami kekalahan dan kekalahan seperti yang sudah-sudah. Berangkat dari situ dirasa perlu strategi baru untuk menghadapi umat Islam itu sendiri, dan strategi itu adalah dengan memanfaatkan umat Islam itu sendiri, mana yang bisa dijadikan kawan dan mana yang bsia dijadikan lawan.

Serangan 11 September 2001 merupakan langkah awal pergerakan dimana menjadikan umat Islam dalang dari semua kerusuhan dan kerusakan, dan memulai politiknya mengajak umat Muslim yang lainnya ikut serta mengutuk penyerangan yang dilakukan 
oleh Muslim radikal, ekstrimis dan radikal, dan menyebut Muslim lain yang bukan bagian dari kelompok diatasa dengan Istilah Moderat. Akan tetapi mereka sendiri belum mengerti apa yang mereka maksud dengan Muslim Moderat dan bagaimana kategorinya. Atau apakah yang mereka maksud dengan Islam moderat berarti Wasathiyah yang ada dalam Islam?

Pada kesempatan kali ini penulis akan mencoba sedikit menjelaskan dan memaparkan istilah yang memiliki dualisme maksud dan tujuan serta landasannya, yaitu antara moderat yang dimaksudkan dan diharapkan oleh Barat terhadap Umat Islam dan moderat / Wasathiyah yang ada dalam Islam.?

\section{B. Berkembangnya Muslim Moderat}

Penggunaan istilah ini yang masih menjadi perdebatan baik dalam kalangan Barat dan Muslim sendiri, yang belum menemukan titik temu dengan apa yang dimaksud oleh istilah Muslim Moderat. Melihat dari awal berkembangnya istilah moderat itu sendiri dalam kalangan Barat terutama Amerika, merupakan respon terhadap serangan yang terjadi pada tanggal 11 september 2001, dengan memojokkan umat Islam sebagai pelaku dan dalang dibalik pengeboman WTC. Tuduhan dialamatkan kepada umat Islam yang beraliran Radikal, Militan, Ekstrimis, Fundamentalis, walaupun mereka belum bisa menginditifikasi kebenaran akan isu dan fitnah yang dimunculkan terhadap umat Islam. Dari sini Daniel Pipes ${ }^{1}$ dalam tulisannya memaparkan "Jika Islam militan menjadi masalah, maka solusinya adalah muslim moderat"

Akan tetapi Daniel Pipes sendiri belum bisa membedakan antara Muslim Militan Dan Muslim Moderat. ${ }^{2}$ Dalam pandangan mereka atau Barat, umat Islam itu hanya ada dua, Radikal dan Moderat. $^{3}$ Tuduhan yang dilemparkan kepada umat Islam menjadikan Amerika harus mengindentifikasi mana umat Islam yang bisa disebut sebagai kawan dan mana yang harus diperangi, karena George Bush menyadari, memerangi umat Islam secara keseluruhan akan menimbulkan ancaman yang sangat besar maka perlu adanya pengindentifikasian, mana umat Islam yang mendukung teroris dan mana yang bisa dijadikan sebagai teman atau mereka sebut dengan istilah Moderat. ${ }^{4}$

Semua skenario yang dijalankan oleh Barat khususnya Amerika, tidak lain dan tidak bukan adalah untuk menekan umat Islam tunduk dan bekrja untuk kepentingan Amerika secara politik dan idiologi, juga tak terlepas

${ }^{1}$ Direktur forum Timur Tengah dan penulis Islam Militan Telah Masuk Amerika, gelar PhD nya dari Harvard dalam kajian sejarah Islam Klasik, dan sekarang mengajar di Hrvard dan Universitas Chicago.

2 Jhon L. Esposito, Dkk, Moderat dan Radikal, cet- I, Jakarta: Referensi, April 2012, hlm. 2.

${ }^{3}$ Baca, Ibid, hlm. 38.

${ }^{4}$ Jhon L. Esposito, Dkk, Moderat, hlm. VI. 
demi kepentingan Israel. Yvonne Yazbeck Haddad $^{5}$ mengutip dari tulisan Martin Peretz " When Amerikca-Hetters Become Americans" “... kemampuan yang ditunjukkan komunitas Muslim dalam mengorganisir, mendaftar pemilih, dan membujuk mereka memilih kandidat tertentu mencemaskan para pendukung Israel. Sebagai seorang Yahudi saya khawatir bahwa kehadiran reputasi yang bertambah, kemakmuran dan ekonomi Muslim akan menjadi bahaya yang nyata bagi kaum Yahudi Amerika."6

Sebelum terjadinya serangan 11 September umat Islam di Amerika telah berhasil memperjuangakan hakhak sipilnya dalam pemerintahan, serta hak pilihnya, dan ini juga merupakan suatu ancaman yang sangat membahayakan akan eksistensi Yahudi dan Amerika dalam kekhawatiran mereka. Dengan memanfaatkan tragedi serta skenario hitam 11 September, Amerika dan pro Yahudi mencoba menginditimidasi umat Islam. ${ }^{7}$

\footnotetext{
${ }^{5}$ Seorang profesor Sejarah Islam dan Hubngan Kristen-Islam di Georgetown University, dan bekerja di Centre for Muslim-Cristian Understanding.

${ }^{6}$ Jhon L. Esposito, Dkk, Modera,t hlm. 19.

${ }^{7}$ Lihat, Ibid, hlm. 13-20.
}

\section{Memahami Istilah Muslim Moderat}

Sampai hari ini belum ada Istilah yang baku untuk mengetahui dengan jelas apa yang dimaksud dengan Muslim moderat. Ia memiliki devenisi sendiri dari sudut pandang yang berbeda. Muqtader $\mathrm{Khan}^{8}$ menyebutkan

"Media Amerika
Menggunakan $r$ istilah
Muslim moderat untuk
muslim yang pro barat
dalam politikya, atau juga
muslim yang slalu kritis
terhadap cara pandang
mereka."9

Muslim moderat juga sering digunakan secara perogatif untuk mengacu kepada mereka yang lebih sekuler dan kurang normatif. Secara umum Muslim moderat di Amerika diartikan dengan penganut islam yang lebih lunak, yang menerima paham demokrasi dan pemisahan antara politik agama dan negara. ${ }^{10}$

Menanggapi Istilah Muslim moderat dan Muslim militan, radikal dan ekstrimis, Muqtader Khan, memaparkan bahwasanya bagi muslim moderat ijtihad merupakan pilihan dan cara yang lebih disukai untuk perubahan sosial, dan politik, sedangkan jihad dengan senajata adalah pilihan terakhir. Dapat dipahami

\footnotetext{
${ }^{8}$ Asisten dosen pada jurusan Ilmu Politik dan hunugan International universitas of Delaware, penulis American Muslims: Bridging Faithand Freedom.

${ }^{9}$ Jhon L. Esposito, Dkk, Moderat, hlm. 6.

${ }^{10}$ Ibid, hlm. 7.
} 
seorang Muslim moderat adalah seseorang yang mendorong kebebsan berfikir, pada saat yang sama menyadari akan pentingnya keimanan. Adapun Muslim radikal dalam pandangannya adalah muslim yang memilih jihad sebagai obsi utama dalam sebuah perubahan. ${ }^{11}$

Yamin Zakaria $^{12}$ mengistilahkan Muslim Moderat itu dengan Neo Modernis $^{13}$ yang bisa disebut dengan liberal, modern, dan berfikir bebas. Dalam kesimpulannya Yamin menilai bahwasanya

"Kelompok neo-Mods ( Neo Modernis ) tidak memiliki posisi kosisten dan mereka selalu mencoba untuk menyatukan apa yang tidak mungkin untuk disatukan, dengan cara memutar balik fakta dan juga karena prinsipprinsio mereka yang tidak logis. Posisi yang tidak konsisten ini hanya akan menambah kebingungan dan membahayakan Muslim dan non-Muslim.",14

Abid Ullah Jan, ${ }^{15}$ menyatakan bahwasanya seorang Muslim tidak bisa

${ }^{11}$ Baca Ibid, hlm. 7-8.

12 Alumni Chemistry dari London University dan Technical Direktor.

${ }^{13}$ Jhon L. Esposito, Dkk, Moderat, hlm. 36.

${ }^{14}$ Ibid, hlm. 43.

15 Seorang komentator yang sering muncul membicarakan Islam dan politik global, Dan sebagai orang yang diasosiasikan dengan pergerakan Islam di Pakistan / Islam Politikism. menjadi menjadi Muslim tanpa menjadi moderat, akan tetapi moderat yang dimaksud disini berbeda dengan moderat yang dipahami oleh Barat atau neo-mods versi Barat yang lebih condong kepada mengerjakan sebagian perintah agama dan meninggalkan sebagian yang lain. Moderat disini adalah bertindak secara tidak berlebihlebihan dalam perkataan, perbuatan dan menjalankan agama. Sesuai dengan petunjuk yang sudah ada dalam agama, sebagai mana tercantum dalam al Quran surat al Baqarah 208

"Hai orang-orang yang beriman, masuklah kamu ke dalam Islam secara keseluruhannya, dan janganlah kamu turut langkah-langkah setan. Sesungguhnya setan itu musuh yang nyata bagimu.",16

yang memerintahkan umat Islam, agar memeluk Islam secara Kaffah. ${ }^{17}$

Louay Safi, ${ }^{18}$ melihat bahwasanya istilah moderat lebih identik dengan sikap politik seseorang yang mengambil poros tengah, yaitu tidak mengambil ekstrim kiri atau kanan dalam spektrum politik, moral, atau agama. Dengan demikian sikap moderat adalah sebuah jebakan dimana pada saat yang bersamaan sikap itu menghilangkan nilai absolutifitas terhadap suatu keyakinan. Seperti yang telah terjadi dalam masyarakat Romawi, dimana umat Kristiani menjalankan agamanya dan nilai-nilai

${ }^{16} \mathrm{QS}$, al Baqarah 208.

${ }^{17}$ Jhon L. Esposito, Dkk, Moderat, hlm. 45-47.

${ }^{18}$ Direktur eksekutif Islamic Society of North Americas LeadershipDecelopment Centre (ILDC) 
keyakinannya dianggap ekstrim dalam masyarakat Romawi sampai pada masa raja Konstantin. ${ }^{19}$

Dalam kamus bahasa Indonesia istilah moderat itu sendiri diartikan dengan

"Selalu menghidarkan perilaku atau pengungkapan yang ekstrim" dan atau "Berkenderungan kearah dimensi atau jalan tengah" 20

\section{Metode Indentifikasi Muslim Moderat dan Tujuan}

Begitu sulitnya dalam mengindentifikasikan bagaimana sosok seroang muslim moderat yang bisa dijadikan kawan oleh Amerika yang hingga hari ini masih menjadi PR besar bagi mereka dan juga FBI. Daniel Pipes dalam pandangannya menyatakan untuk mengenditifikasi seorang Muslim moderat adalah dengan menyelami track record umum atau pribadi seorang muslim tersebut baik dari internet, cetakan, lokal, asing dari seseorang atau lembaga, dan dari buku serta karya tulis. Disamping itu yang tidak kalah pentingnya adalah melontarkan pertanyaan-pertanyaan yang lebih spesifik, pertanyaan untuk melihat cara pandanh seorang Muslim terhadap :

\section{Masalah kekerasan}

${ }^{19}$ Jhon L. Esposito, Dkk, Moderat, hlm. 198.

${ }^{20}$ Meity Taqdir Qadratillah, dkk, Kamus Bahasa Indonesia untuk Pelajar, Jakarta: Badan Pengenmbangan dan Pembinaan Bahasa Kementrian Kebudayaan dan Pendidikan, 2011, hlm. 327.
Apakah anda menantang atau mengutuk orang Palestina, Chechnya dan orang-orang Kashmir yang mengakhiri hayatnya untuk membunuh pihak sipil dari musuh?

Apakah anda akan mengutuk dengan memberi nama sebagai kelompok teroris kepada organisasi seperti Abu Sayyaf, Al Jama'ah al Islamiyah, Islamique Armee, Hamas, Harakat al Mujahidin, Hizbullah dan al Qaeda? ${ }^{21}$

\section{Sikap Modernitas}

Apakah perempuan harus mempunyai hak yang sama dengan laki-laki dalam hal warisan dan kesaksian?

Apakah jihad masih dapat diterima di dunia dewasa ini?

Apakah anda menerima kevalidisan agama selain Islam?

Apakah ada yang bisa ditauladani oleh umat Islam dari Barat? ${ }^{22}$

\section{Paham sekularisasi}

Bolehkah Muslim pindah agama ke agama lain?

Apakah perempuan Muslim boleh menikah dengan pria non Muslim?

Apakah anda menerima perundangan dari pemerintahan yang mayoritas non Muslim dan taat sepenuhnya tanpa syarat?

Ketika ajaran Islam bertentangan dengan hukum-hukum sekuler, yang mana yang harus mengalah? ${ }^{23}$

\footnotetext{
${ }^{21}$ Jhon L. Esposito, Dkk, Moderat, hlm. 3.

${ }^{22}$ Ibid, hlm. 21.
} 


\section{Sikap Pluralisme}

Apakah Sufi dan Syi'ah termasuk Muslim yang sah?

Apakah anda melihat orang yang tidak sependapat dengan anda termasuk kafir?

\section{Muslim yang kritis / Self Criticism}

Apakah anda bisa menerima legtimasi dari penelitian sarjana tentang asal usul Islam?

Siapa yang bertanggung jawab atas pengeboman bunuh diri 9/11?

\section{Versus Islam militan}

Apakah anda dapat menerima tindakan keamanan yang lebih baik untuk memerangi Islam militan?

Apakah anda setuju, bahwa lembaga-lembaga yang dituduh mendanai teroris harus tutup, atau apakah anda melihat kejala ini sebagai bias? $?^{24}$

\section{Perspektif terhadap Barat}

Apakah anada dapat menerima negara Barat yang mayoritas Kristen dan sekular sebagaimana adanya, atau apakah anda berusaha untuk merobahnyamenjadi negara mayoritas Muslim yang diatur degnan hukum Islam? $?^{25}$

\section{Dari bentuk-bentuk pertanyaan diatas dapat kita simpulkan.}

\footnotetext{
${ }^{23}$ Jhon L. Esposito, Dkk, Moderat, hlm. 21.

${ }^{24} \mathrm{Ibid}$, hlm. 4.

${ }^{25}$ Ibid, hlm. 5.
}

Bahwasanya dalam pandangan Barat seorang muslim moderat itu adalah seorang muslim yang berpandangan sekuler, sesuai degan pernyataan Pipes, seorang muslim yang moderat adalah seorang muslim yang sekuler, serta membenarkan politik serta propaganda yang dilakukan oleh pemerintahan Amerika terhadap kebijak-kebijakan yang mereka perbuat, dan menjadikan setiap muslim itu pluralis. termasuk yang tak kalah pentingnya adalah, dimana mereka ingin memanfaatkan umat Islam untuk memukul umat Islam sendiri.

\section{Moderat Dalam Pandangan Islam}

Dalam agama Islam istilah moderat adalah arti dari sebuah kata wasathiyah, dalam al Quran Allah Swt menyebutkan bahwasanya umat Islam adalah umat yang wasathiyah Qs, al Baqarah ayat 143.

Dan demikian Kami telah menjadikan kalian (umat Islam) umat pertengahan agar kalian menjadi saksi atas (perbuatan) manusia dan agar Rasul (Muhammad) menjadi saksi atas (perbuatan) kalian. Dan Kami tidak menetapkan kiblat yang menjadi kiblatmu (sekarang) melainkan agar Kami mengetahui (supaya nyata) siapa yang mengikuti Rasul dan siapa yang membelot. Dan sungguh (pemindahan kiblat) itu terasa amat berat, kecuali bagi orang-orang yang telah diberi petunjuk oleh Allah; dan Allah tidak akan menyia-nyiakan imanmu. Sesungguhnya Allah Maha Pengasih 
lagi Maha Penyayang kepada manusia. ${ }^{26}$

Dr. Muhammad $\operatorname{Imarah}^{27}$ menjelaskan bahwasanya wasathiyah yang ada dalam Islam adalah

"Kebenaran diantara dua kebathilan, keadilan ditengah dua kezaliman, tengah-tengah diantara ekstriminitas yang menolak eksageritas $^{28}$, sebab berlebihan bertentangan dengan wasathiyah yang berarti keberpihakan terhadap salah satu dua kutup yang ada dan berdiri pada salah satu dua anak timbangan. ${ }^{29}$

Jadi wasathiyah dalam Islam adalah suatu sikap ketiga yang tidak berpihak terhadap salah satu kubu yang bertentangan, akan tetapi memiliki keistimewaan yang dapat merangkul dan mengkombinasikan unsur-unsur yang dapat dirangkul dan dikombinasikan sebagai suatu keharmonisan yang tidak saling memusuhi antara dua kutub yang berlwanan.

Dalam hadis riwayat Imam Ahmad, wasath adalah keadilan, kami menjadikan kamu satu umat yang adil (pilihan). ${ }^{30}$

Kata-kata moderat menurut Dr. Imarah tidaklah dapat mendefenisikan dan memenuhi dari arti wasathiyah /

${ }^{26}$ Qs, al Baqarah 143.

27 Dosen Aqidah Filsafah Universita al Azhar, Kairo- Mesir.

${ }^{28}$ Sikap berlebihan

29 Muhammad Imarah, Perang Terminologi: Islam Versus Barat, Terjemahan " Ma'rakah al Musthalahat Bayna al Gharb wa al Islam", Jakarta: Rabbani Pres, 1998, hlm. 266.

${ }^{30}$ Hr. Imam Ahmad. keadilan yang ada dalam Islam, apalagi diartikan moderat adalah tunduk pada kenyataan, malah akan lebih berbahaya lagi kalau kenyataan itu jahat, dan ini sangat bertentangan dengan Islam, bahkan wasathiyah bisa menjadi lawan dari moderat. ${ }^{31}$

Dalam al Quran banyak menunjukkan dan karakter wasathiyah Islam, dalam surat al Fatihah ayat 7 Allah Swt berfirman

Yaitu jalan orang-orang yang telah Engkau beri ni'mat kepada mereka; bukan (jalan) mereka yang dimurkai dan bukan (pula jalan) mereka yang sesat. ${ }^{32}$

Yang dimaksud dengan Maghdub (Murkai) di sini adalah orang-orang Yahudi dan Dhallin (sesat) adalah orang-orang Nasrani, agar kita menjalankan agama Islam ini tidak seperti mereka. ${ }^{33}$

Imam At Tirmidzi meriwayatkan, Nabi Saw bersabda:

" Jalan yang dibenci adalah Yahudi dan yang sesat adalah Nashara."34

Dalam surat al Furqan ayat 67.

Dan orang-orang yang apabila membelanjakan (harta), mereka tidak berlebih-lebihan, dan tidak (pula)

31 Baca, Imarah, Perang Terminologi, hlm. 267.

${ }^{32}$ Qs, al Fatihah, 7.

33 Syaikhul islam Ibnu Taimiyah rahimahullah menyebutkan dalam kitab iqtidla Shirathil Mustaqim bahwa Yahudi dibenci karena berilmu tapi tidak beramal, dan kaum Nasrani sesat karena mereka rajin beramal tanpa ilmu sehingga berbuat bid'ah dalam agama.

${ }^{34} \mathrm{Hr}$, Imam Tirmidzi. 
kikir, dan adalah (pembelanjaan itu) di tengah-tengah antara yang demikian. ${ }^{35}$

Firman Allah ini bertujuan agar kita tidak terlalu boros dan juga tidak terlalu kikir dalam menginfakkan dan mengggunakan harta.

Jadi Wasathiyah dalam Islam adalah mencerminkan karakter dan jati diri yang khusus dimiliki oleh manhaj Islam dalam pemikiran dan kehidupan, dalam pandangan pelaksanaan dan penerapan, ${ }^{36}$ yang memadukan antara konsep ruh dan jasad, dunia dan akhirat, agama dan negara, subjek dan objek, individu dan msyarakat, pemikiran dan realitas, materi dan idealisme, yang riil dan yang ideal, tujuan dan cara, yang lama dan yang baru, pokok dan cabang, akal dan naql, primodial dan global, kebenaran dan kekuatan, ijtihad dan taqlid, agama dan ilmu dan dualisme-dualisme yang lainnya. ${ }^{37}$

\section{PENUTUP}

Perspektif Barat dan Islam terhadap Istilah Moderat sangatlah jauh berbeda, baik dari segi pemaknaan dan tujuan. Dalam pandangan barat Moderat digunakan sebagai alat untuk menjadikan umat Islam kawan yang pro terhadap semua kebijakan dan pandangan hidup yang ada di Barat, serta menentang dengan apa yang mereka sebut muslim militan, radikal dan lain-lain dari berbagai macam istilah yang mereka tempelkan terhadap umat Islam. Adapun yang

${ }^{35}$ Qs. Al Fuqan, 67.

${ }^{36}$ Imarah, Perang Terminologi, hlm. 265.

${ }^{37}$ Ibid, hlm. 269. terkandung dalam istilah moderat dalam pandangan Barat adalah menmbentuk umat Islam dalam satu waktu menjadi sekuler, Pluralis, Anti Ekstrimis/ Anti Islam Radikal / Militan, modernis, dan mengamini apa yang ada di Barat. Wacana tinggal wacana, sampai detik ini mereka belum bisa membentuk dan mengindetifikasi bagaimanakah sosok seorang muslim yang moderat sesuai dengan apa yang mereka harapkan.

Dalam Islam, moderat atau yang kita kenal dengan wasathiyah, merukan bagian yang tidak bisa terpisahkan dari Islam dan umat Islam itu sendiri, yang sudah menjadi manhaj dalam hidup dalam menjalani kehidupan beragama dan bersosial bagi diri setiap muslim. Wasathiyah dalam Islam merupakan solusi dari setiap permsalahan kehidupan yang ada, dimana setiap Muslim bisa bersikap adil dalam setiap kondisi dan keadaan yang dihadapinya dan wasathiyah dalam Islam bukan berarti stagnan. Wallahu A'lami bi al Shawab.

\section{Al-Quran}

\section{DAFTAR PUSTAKA}

Hadis Nabi

Esposito, Jhon L., Dkk, Moderat dan

Radikal, cet- I, Jakarta:

Referensi, April 2012.

Imarah, DR. Muhammad, Perang

Terminologi: Islam Versus Barat,

Terjemahan " Ma'rakah al

Musthalahat Bayna al Gharb wa 
110 Jurnal Al-Aqidah, Volume 10, Edisi 2, Desember 2018

al Islam”, Jakarta: Rabbani Pres, 1998.

Qadratillah, Meity Taqdir, dkk, Kamus Bahasa Indonesia untuk Pelajar, Jakarta: Badan Pengenmbangan dan Pembinaan Bahasa Kementrian Kebudayaan dan Pendidikan, 2011. 